Pathophysiology

of Haemostasis and Thrombosis

\title{
Hemextin AB Complex - A Snake Venom Anticoagulant Protein Complex That Inhibits Factor VIla Activity
}

\author{
Yajnavalka Banerjee $^{a}$ Jun Mizuguchi ${ }^{b}$ Sadaaki Iwanaga ${ }^{b}$ \\ R. Manjunatha Kini ${ }^{\mathrm{a}, \mathrm{c}}$ \\ ${ }^{a}$ Protein Science Laboratory, Department of Biological Sciences, Faculty of Science, National University of \\ Singapore, Singapore; ${ }^{b}$ Blood Products Research Department, The Chemo-Sero-Therapeutic Research Institute, \\ Kumamoto, Japan; ${ }^{\mathrm{C}}$ Department of Biochemistry, VCU Medical Center, Medical College of Virginia, \\ Virginia Commonwealth University, Richmond, Va., USA
}

\section{Key Words}

Anticoagulant $\cdot$ Synergism · Extrinsic tenase complex $\cdot$ Factor VIla $\cdot$ Tissue factor $\cdot$ Three-finger toxin $\cdot$ Snake venom

\begin{abstract}
Snake venom is a veritable gold mine of bioactive molecules, capable of binding to a wide variety of pharmacological targets, including the blood coagulation cascade. Here, we report the isolation and characterization of two synergistically acting anticoagulant three-finger proteins, hemextin $A$ and hemextin $B$, from the venom of Hemachatus haemachatus (African Ringhals cobra). Hemextin A but not hemextin B exhibits mild anticoagulant activity. However, hemextin $B$ interacts with hemextin $A$ and forms a complex (hemextin $A B$ complex), and synergistically enhances its anticoagulant potency. Prothrombin time assay showed that these two proteins form a 1:1 complex. Using a 'a dissection approach', we found that hemextins $A$ and $A B$ complex prolong clotting
\end{abstract}

This work is supported by a Program grant from Biomedical Research Council, Singapore.
(C) 2005 S. Karger AG, Basel

$1424-8832 / 05 / 0345-0184 \$ 22.00 / 0$

Fax +4161306 1234 E-Mail karger@karger.ch www.karger.com by inhibiting extrinsic tenase activity. Further studies showed that hemextin $A B$ complex potently inhibits the proteolytic activity of factor VIIa (FVIla) and its complexes. Kinetic studies showed that hemextin AB complex is a non-competitive inhibitor of FVIla-soluble tissue factor proteolytic activity with a $\mathrm{K}_{\mathrm{i}}$ of $25 \mathrm{nM}$. Hemextin $A B$ complex is the first reported natural inhibitor of FVIla that does not require either tissue factor or factor $\mathrm{Xa}$ scaffold to mediate its inhibitory activity. Molecular interactions of hemextin $\mathrm{AB}$ complex with FVIla/tissue factor-FVIla may provide a new paradigm in the search for anticoagulants inhibiting the initiation of blood coagulation.

Copyright $(2005$ S. Karger AG, Basel

\section{Introduction}

Snake venoms contain a wide array of bioactive molecules, which bind to various target proteins and have a wide variety of pharmacological effects [1]. Several of these molecules influence blood coagulation and have inspired the design and development of therapeutic agents for cardiovascular diseases [2]. Therefore, to search for new lead molecules we and others have focused on isolat- 




Fig. 1. Purification of hemextins A and B. a Size-exclusion chromatography of the crude venom of $H$. haemachatus venom on Superdex 30 column. Inset: anticoagulant activity of peaks 2 and 3. b Cation exchange chromatography of peak 3 on Uno S6 column.

ing and characterizing proteins from snake venoms that affect blood coagulation. In this study, we report the purification and characterization of a three-finger toxin from the venom of Hemachatus haemachatus (African Ringhals cobra) that exhibits anticoagulant activity. Although it has mild anticoagulant activity, its synergistic interaction with the second three-finger toxin enhances its anticoagulant potency. The anticoagulant protein and its complex specifically inhibit factor X (FX) activation by tissue factor-factor VIIa (TF-FVIIa) complex by noncompetitively inhibiting FVIIa proteolytic activity. This is the first report of a naturally occurring FVIIa inhibitor, which does not require either the TF or FXa scaffold for its anticoagulant activity.

\section{Experimental Procedures}

\section{Materials}

Lyophilized $H$. haemachatus venom was obtained from African Reptiles and Venoms, Gauteng, South Africa. Human plasma-derived FVIIa was a gift from Kaketsuken, Japan. All other chemicals and reagents used were of highest purity available.

\section{Purification of Anticoagulant Protein}

$H$. haemachatus crude venom (100 mg in $1 \mathrm{ml}$ distilled water) was applied to a Superdex 30 gel filtration column $(1.6 \times 60 \mathrm{~cm})$ equilibrated with $50 \mathrm{~m} M$ Tris- $\mathrm{HCl}$ buffer ( $\mathrm{pH}$ 7.4) and eluted using the same buffer, using a ÄKTA Purifier system (Amersham Biosciences, Uppsala, Sweden). Individual fractions were assayed for anticoagulant activity. Active fractions were pooled and sub-fractionated on a Uno S-6 (Bio-Rad, Hercules, Calif., USA; column volume, $6 \mathrm{ml}$ ) cation-exchange column. The anticoagulant peaks obtained from cation-exchange were rechromatographed to purity using RP-HPLC on a Jupiter C18 $(1 \times 25 \mathrm{~cm})$ column. The homogeneity and mass of the proteins were determined with electrospray ionization mass spectrometry using a Perkin-Elmer Sciex API-300 LC/MS/MS system. $\mathrm{NH}_{2}$-terminal sequencing of the native and Spyridylethylated proteins were performed by automated Edman degradation using a Perkin-Elmer Applied Biosystems 494 pulsedliquid phase sequencer (Procise).

\section{Anticoagulant Activity and Inhibitory Specificity}

The anticoagulant activities of $H$. haemachatus venom and its fractions were determined using a BBL fibrometer by using recalcification time [3], prothrombin time [4], Stypven time [5] and thrombin time [6] assays. The selectivity profile of anticoagulant proteins and their complex was examined against procoagulant serine proteases (FIXa, FXa, FXIa, FXIIa, plasma kallikrein and thrombin), anticoagulant serine protease, fibrinolytic serine proteases (urokinase, tissue plasminogen activator and plasmin) and classical serine proteases (trypsin and chymotrypsin).

\section{Kinetics of Inhibition}

The inhibitory potency of anticoagulant complex was measured over a range of substrate concentrations. Reactions with FVIIa-sTF contained $0.0125-0.05 \mu M$ of inhibitor complex and $0-3 \mathrm{mM}$ of $\mathrm{S}-2288$. The initial velocities were measured over $5 \mathrm{~min}$ under steady-state conditions and were fit by reiterative nonlinear regression to equation (1), describing a classical non-competitive inhibitor, to derive the $K_{i}$ value.

$$
1 / \mathrm{V}=\mathrm{K}_{\mathrm{m}} / \mathrm{V}_{\max }\left(1+[\mathrm{I}] / \mathrm{K}_{\mathrm{i}}\right) 1 /[\mathrm{S}]+1 / \mathrm{V}_{\max }\left(1+[\mathrm{I}] / \mathrm{K}_{\mathrm{i}}\right)
$$

\section{Results and Discussion}

\section{Purification of the Anticoagulant Protein}

Crude venom of $H$. haemachatus exhibited potent anticoagulant activity in both recalcification and prothrombin time assays (data not shown). To purify the anticoagulant protein, the crude venom was size fractionated by gel filtration chromatography (fig. 1a). Fractions corresponding to peaks 2 and 3 contained anticoagulant proteins as determined by prothrombin time assays. Peak 2 (contains anticoagulant $\mathrm{PLA}_{2}$ which has been characterized earlier [7]) had milder anticoagulant activity compared to peak 3 (inset fig. 1a). Therefore, anticoagulant proteins from peak 3 were isolated in these studies. Peak 3 was fractionated using cation-exchange chro- 
matography (fig. 1b). Only peak-labeled hemextin A exhibited mild anticoagulant activity. Preliminary studies showed that the anticoagulant activity of peak hemextin A was potentiated by peak-labeled hemextin B (see below). Since this anticoagulant complex specifically inhibited the extrinsic tenase complex (described below), we named it as hemextin $\mathrm{AB}$ complex (Hemachatus extrinsic tenase inhibitor) and the individualproteins hemextins $\mathrm{A}$ and $\mathrm{B}$, respectively. Fractions corresponding to both hemextins A and B were pooled separately and purified using RP-HPLC (data not shown). The masses of hemextins A and B were determined by electrospray ionization mass spectrometry as $6,835.00 \pm 0.52$ and $6,792.56 \pm 0.32 \mathrm{Da}$, respectively. The $\mathrm{NH}_{2}$-terminal sequence of first 25 amino acid residues of native and pyridylethylated hemextins $\mathrm{A}$ and $\mathrm{B}$ were determined. Both hemextins A and B show similarity to proteins belonging to the three-finger toxin family (data not shown).

\section{Anticoagulant Activity}

The anticoagulant activity of hemextins A and B was determined using prothrombin time assay. Hemextin A exhibited a mild anticoagulant activity. Hemextin B even at higher concentrations did not affect clotting time. Interestingly, an equimolar mixture of hemextins A and B exhibited potent anticoagulant activity indicating complex formation between the proteins (data not shown). Complex formation between the two proteins was further investigated by a titration experiment in the prothrombin time assay. The concentration of hemextin A was kept constant at $4.4 \mu M$ and its anticoagulant activity was monitored with increasing hemextin B concentrations. The anticoagulant activity increased with the increasing concentrations of hemextin B until the ratio reached 1:1. Further addition did not increase the anticoagulant effect (data not shown). The results indicated hemextins A and B form a 1:1 complex and complex formation is crucial for potent anticoagulant activity.

The site of activity of the proteins and their complex were determined with the help of 'dissection approach' $[8,9]$. Results showed that hemextins A and AB complex affect only the prothrombin time but not the Stypven time and thrombin time, whereas hemextin B does not have any anticoagulant activity (data not shown). Further only hemextins $\mathrm{A}$ and $\mathrm{AB}$ complex but not hemextin $\mathrm{B}$ inhibit the activation of FX by the reconstituted TF-FVIIa complex (data not shown). Thus, hemextins $\mathrm{A}$ and $\mathrm{AB}$ complex inhibit only the extrinsic tenase complex.

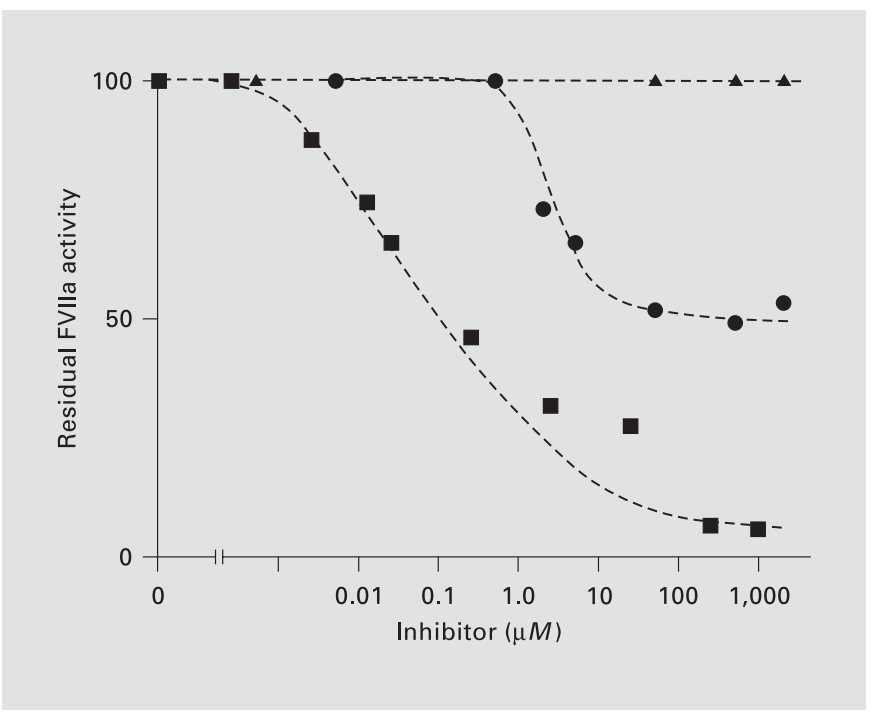

Fig. 2. Inhibition of FVIIa activity. The inhibitory potency of hemextin A $(\bullet)$, hemextin B $(\boldsymbol{\Delta})$ and hemextin AB complex ( $\boldsymbol{\square})$ for the inhibition of FVIIa.

\section{Specificity and Kinetics of Inhibition}

Specificity of inhibition was determined by screening hemextins $\mathrm{A}$ and $\mathrm{B}$ and their complex against 12 different serine proteases. No inhibitory activity was observed against any of the serine proteases with the exception of FVIIa and its complex with TF and plasma kallikrein (fig. 2). However, the inhibitory potency towards FVIIa was at least 50 times higher than towards plasma kallikrein (data not shown). Kinetic studies revealed that hemextin $\mathrm{AB}$ complex is non-competitive inhibitor of FVIIa-sTF activity with a $\mathrm{K}_{\mathrm{i}}$ of $25 \mathrm{n} M$ (data not shown). Some other anticoagulants from snake venoms also inhibit extrinsic tenase complex. However, they are not as specific [10].

\section{Hemextin AB Complex Is a Unique Protein Complex}

Synergism among snake venom toxins is fairly well characterized, particularly among presynaptic neurotoxins $[11,12]$. However, most of these protein complexes contain $\mathrm{PLA}_{2}$ as an integral part. Rhodocetin and group $\mathrm{C}$ prothrombin activators are the only other non-covalent snake venom protein complexes that do not contain $\mathrm{PLA}_{2}$ $[13,14]$. Hemextin AB complex is a unique protein complex formed by the interaction between two three-finger toxins.

So far, only two specific natural inhibitors of TFFVIIa complex have been well characterized: tissue factor pathway inhibitor and nematode anticoagulant pro- 
tein c2. Both the inhibitors form a quaternary complex with TF-FVIIa-FXa and in both, the active site of FVIIa is occupied by respective inhibitors and is not accessible $[15,16]$. Unlike tissue factor pathway inhibitor and nematode anticoagulant protein $\mathrm{c} 2$, hemextin $\mathrm{AB}$ complex does not require either TF or FXa scaffold for its antico- agulant activity and the active site of FVIIa is accessible even after its binding. Therefore, hemextins $\mathrm{A}$ and $\mathrm{AB}$ complex are novel inhibitors of FVIIa and TF-FVIIa complex. This new anticoagulant may help us develop different strategies and therapeutic agents to inhibit the initiation step in blood coagulation.

\section{References}

1 Hutton RA, Warrell DA: Action of snake venom components on the haemostatic system. Blood Rev 1993; 7:176-189.

$\checkmark 2$ Markland FS: Snake venoms and the hemostatic system. Toxicon 1998;36:1749-1800.

-3 Langdell RD, Wagner RH, Brinkhous KM: Effect of antihemophilic factor on one-stage clotting tests; a presumptive test for hemophilia and a simple one-stage antihemophilic factor assy procedure. J Lab Clin Med 1953;41:637_ 647.

4 Quick AJ: The prothrombin time in haemophilia and in obstructive jaudice. J Biol Chem 1935;109:73-74.

5 Hougie C: Effect of Russell's viper venom (stypven) on Stuart clotting defect. Proc Soc Exp Biol Med 1956;98:570-573.

-6 Jim R: A study of the plasma thrombin time. J Lab Clin Med 1957;50:45-60.

$\checkmark 7$ Condrea E, Fletcher JE, Rapuano BE, Yang CC, Rosenberg P: Effect of modification of one histidine residue on the enzymatic and pharmacological properties of a toxic phospholipase A2 from Naja nigricollis snake venom and less toxic phospholipases A2 from Hemachatus haemachatus and Naja atra snake venoms. Toxicon 1981;19:61-71.
Kini RM, Banerjee Y: Dissection approach: a simple strategy for the identification of the step of action of anticoagulant agents in the blood coagulation cascade. J Thromb Haemost 2005; 3:170-171.

-9 Stefansson S, Kini RM, Evans HJ: The inhibition of clotting complexes of the extrinsic coagulation cascade by the phospholipase A2 isoenzymes from Naja nigricollis venom. Thromb Res 1989;55:481-491.

10 Kini RM, Evans HJ: The role of enzymatic activity in inhibition of the extrinsic tenase complex by phospholipase A2 isoenzymes from Naja nigricollis venom. Toxicon 1995;33: 1585-1590.

11 Doorty KB, Bevan S, Wadsworth JD, Strong PN: A novel small conductance $\mathrm{Ca} 2+$-activated $\mathrm{K}+$ channel blocker from Oxyuranus scutellatus taipan venom. Re-evaluation of taicatoxin as a selective $\mathrm{Ca} 2+$ channel probe. $\mathrm{J}$ Biol Chem 1997;272:19925-19930.
12 Habermann E, Breithaupt H: Mini-review. The crotoxin complex - an example of biochemical and pharmacological protein complementation. Toxicon 1978;16:19-30.

13 Rao VS, Kini RM: Pseutarin C, a prothrombin activator from Pseudonaja textilis venom: its structural and functional similarity to mammalian coagulation factor $\mathrm{Xa}-\mathrm{Va}$ complex. Thromb Haemost 2002;88:611-619.

14 Wang R, Kini RM, Chung MC: Rhodocetin, a novel platelet aggregation inhibitor from the venom of Calloselasma rhodostoma (Malayan pit viper): synergistic and noncovalent interaction between its subunits. Biochemistry 1999; 38:7584-7593.

15 Lindhout T, Franssen J, Willems G: Kinetics of the inhibition of tissue factor-factor VIIa by tissue factor pathway inhibitor. Thromb Haemost 1995;74:910-915.

16 Lee AY, Vlasuk GP: Recombinant nematode anticoagulant protein $\mathrm{c} 2$ and other inhibitors targeting blood coagulation factor VIIa/tissue factor. J Intern Med 2003;254:313-321. 